\title{
Estimates of Marketable Yield in Asparagus using Fern Vigor Index and a Minimum Number of Daily Harvest Records
}

\author{
D.J. Wolyn \\ Department of Horticultural Science, University of Guelph, Guelph, Ont., N1G 2W1, Canada \\ Additional index words. Asparagus officinalis, correlation, percent marketable yield, predictive model
}

\begin{abstract}
Fern vigor indices and estimates of percent marketable yield (PMY) were used to determine alternative measures of asparagus (Asparagus officinalis L.) marketable yield. Total yield was highly correlated $(0.75 \leq r \leq 0.91)$, and marketable yield was not correlated with fern vigor indices. The products of fern vigor indices and seasonal PMYs were highly predictive of marketable yield $(r$ 20.95). When the products of each daily PMY estimate and fern vigor index for the same season were determined, then averaged over years, $<30 \%$ of correlations with marketable yield were $\geq 0.90$, and $r$ values varied considerably during the season. The products, averaged for 2 years, of fern vigor index and mean PMY estimated from combinations of three harvest dates during the season, except from the first harvest week, were associated with marketable yield. For the 40 3-day average estimates of PMY examined, 95\% of Pearson correlation coefficients were $\geq 0.90$ and all were $\geq 0.88$. Thus, fern vigor index and PMY estimates from three harvest dates may be used to predict temperate zone marketable yield, decreasing labor requirements for yield trials, and facilitating evaluation of many experimental hybrids.
\end{abstract}

Daily harvests and hand-grading of asparagus spears adds considerable expense to breeding efforts. Reliable, but less expensive yield estimates that discriminate among experimental hybrids for marketable yield would increase efficacy of breeding programs significantly. As labor requirements decrease, more hybrids can be tested, enhancing cultivar development.

Alternate estimates of total yield have been identified. Early yield was highly correlated with seasonal yield in the United States (Ellison et al., 1960, Ito and Currence, 1965) but not in New Zealand (Bussell et al., 1987). Total harvested yield was associated with number of stalks during the summer (Currence and Richardson, 1937; Moon, 1976; Young, 1937) or a stalk yield index that considered both stalk count and diameter (Ellison and Scheer, 1959).

Since asparagus may be harvested for a decade or more, associations between years could lessen the need for data collection in every season. Total yields and stalk counts were highly correlated between consecutive years (Coyne, 1967; Currence and Richardson, 1937; Moon, 1976). Marketable yields from the first two harvest seasons were related to cumulative yields after 4 to 6 years (Bussell et al., 1987). However, second to fourth season yields were not associated with those from years 9 and 10 (Falloon and Nikoloff, 1986).

Marketable yield, a modified Canada \#1 grade, is the primary selection criterion for the Univ. of Guelph breeding program and may not necessarily be correlated with total yield because hybrids can vary significantly for the proportion of marketable spears. The objective of this study was to determine if a fern vigor index and an estimate of percent marketable yield (PMY) requiring minimum harvest data could be used to predict marketable yield and provide a low-cost means of evaluating experimental asparagus hybrids.

Received for publication 7 July 1992. Accepted for publication 14 Nov. 1992. This research was supported by the Natural Science and Engineering Research Council of Canada, the Ontario Ministry of Agriculture and Food, and the Canadian Horticultural Council. I thank J. Wacasey and B. Earngy for technical support. The cost of publishing this paper was defrayed in part by the payment of page charges. Under postal regulations, this paper therefore must be hereby marked advertisement solely to indicate this fact.

\section{Materials and Methods}

Plant material. Twelve genotypes selected from open-pollinated cultivars in grower fields, 'G106', 'G112', 'G120', 'G122', 'G130', 'G132', 'G183', 'G185', 'G189', 'G193', and 'G199', were micropropagated to produce plantlets (Jamieson et al., 1985), and one cultivar, Viking, was grown from seed to produce crowns. The twelve lines originated from 'UC66', 'Mary Washington', 'Delmonte 361', and 'Viking.' Transplants were grown in the greenhouse for 10 weeks before field planting during May 1983.

Field design. Thirty-two plants for each genotype were grown in each of four replications in a randomized complete-block design at the Cambridge Research Station, Cambridge, Ont., in a Lisbon Sandy Loam, Buford Fox series, an Orthic Gray-Brown Luvisol. Rows were spaced at $1.5 \mathrm{~m}$, and plants were spaced at $0.45 \mathrm{~m}$ within rows. Seedlings were planted in a $20 \mathrm{~cm}$ deep furrow. During the first season, trenches were gradually filled to cover the crowns to a $20 \mathrm{~cm}$ depth. The first harvest occurred in 1985 for 2 weeks and then for 6 or 7 weeks in subsequent years; but yields for this experiment were recorded only in 1990 and 1991.

Data collection and analysis. Data were collected for the first 10 of the 32 plants in a row that constituted a plot. In Aug. 1989, 1990, and 1991, stalk diameters were measured $2.5 \mathrm{~cm}$ above the soil, and fern vigor indices were calculated for each plant as: total fern index $(\mathrm{TFI})=3 \times($ no. of large stalks, $>15 \mathrm{~mm})+2 \times($ no. of medium stalks, 10 to $15 \mathrm{~mm}$ ) $+1 \times$ (no. of small stalks, $<10 \mathrm{~mm}$ ) (Ellison and Scheer, 1959), and amodification of this index, largemedium fern index $($ LMFI $)=3 \times($ no. of large stalks $)+2 \times($ no. of medium stalks). In Spring 1990 and 1991, spears were harvested for 6 to 7 weeks and evaluated as marketable-Canada \#1 (Table 1) or cull. Plots were harvested daily except during periods of low temperatures when growth was slow. PMY for each plant was calculated as (marketable yield/total yield) $\times 100$.

Fern indices, stalk count, spear count, total yield, and marketable yield were summed for the 10 plants in each plot and averaged over replications and years. Pearson correlation coefficients were calculated among yield variables and, also, between marketable

Abbreviations: LMFI, large-medium fern index; PMY, percent marketable yield; TFI, total fern index; TFN, total fern number. 
Table 1. Modified Canada no. 1 asparagus grading standards.

\begin{tabular}{|c|c|c|c|c|}
\hline Factors & \multicolumn{4}{|l|}{ Standards } \\
\hline Length & \multicolumn{4}{|c|}{ Between 15 and $23 \mathrm{~cm}$} \\
\hline Diameter & \multicolumn{4}{|c|}{ At least $8 \mathrm{~mm}$ when measured at a point $11.5 \mathrm{~cm}$ from extreme tip } \\
\hline Shape & \multicolumn{4}{|c|}{$\begin{array}{l}\text { Not badly deformed such as flattened, doubled, or crooked. The tip } \\
\text { should curl no more than } 45^{\circ} \text { from the stalk. }\end{array}$} \\
\hline Spreading tips & \multicolumn{4}{|c|}{$\begin{array}{l}\text { Upper tow-third portion of the tip must be free from apparent seedy or } \\
\text { branched appearance. }\end{array}$} \\
\hline Broken tips & \multicolumn{4}{|c|}{ No more than the extreme tip may be missing. } \\
\hline Butts & \multicolumn{4}{|c|}{$\begin{array}{l}\text { Spears free from white butts, doubles, and hollow centers. Trim to meet } \\
\text { standard when possible. }\end{array}$} \\
\hline Disease & \multicolumn{4}{|c|}{ Not more than two discolored bracts or scales resulting from rust. } \\
\hline Insects & \multicolumn{4}{|c|}{$\begin{array}{l}\text { Free from damage that causes scarring of }>1.3 \mathrm{~cm} \text { in diameter in } \\
\text { aggregate and free of eggs or larvae. }\end{array}$} \\
\hline Frost damage & \multicolumn{4}{|c|}{$\begin{array}{l}\text { Free from signs of tissue breakdown such as watery, glazed, discolored, } \\
\text { or blanched appearance. }\end{array}$} \\
\hline $\begin{array}{l}\text { Fern } \\
\text { variables }\end{array}$ & $\begin{array}{l}\text { Marketable } \\
\text { yield }\end{array}$ & $\begin{array}{l}\text { Total } \\
\text { yield }\end{array}$ & $\begin{array}{l}\text { Marketable spear } \\
\text { (no.) }\end{array}$ & $\begin{array}{l}\text { Total spear } \\
\text { (no.) }\end{array}$ \\
\hline $\mathrm{TFI}^{\mathrm{x}}$ & $0.12^{\mathrm{NS}}$ & $0.75^{* *}$ & $-0.13^{\mathrm{NS}}$ & $0.94^{* *}$ \\
\hline TFI $\times \mathrm{PMY}^{\mathrm{w}}$ & $0.95^{* *}$ & & & \\
\hline $\begin{array}{l}\text { LMFI }^{v} \\
\text { LMFI } \times \text { PMY }\end{array}$ & $\begin{array}{l}0.26^{\mathrm{NS}} \\
0.96^{* *}\end{array}$ & $0.91^{* *}$ & $0.14^{\mathrm{NS}}$ & $0.68^{*}$ \\
\hline $\begin{array}{l}\text { TFN }^{u} \\
\text { TFN } \times \text { PMY }\end{array}$ & $\begin{array}{r}-0.24^{\mathrm{NS}} \\
0.89^{* *}\end{array}$ & $0.59^{*}$ & $-0.22^{\mathrm{NS}}$ & $0.88^{* *}$ \\
\hline \multicolumn{5}{|c|}{$\begin{array}{l}{ }^{2} \text { Mean } 1989,1990,1991 . \\
\text { yMean } 1990,1991 . \\
{ }^{x} \text { Total fern index }=3 \times(\text { no. of large stalks, }>15 \mathrm{~mm})+2 \times(\text { no. of medium stalks, } 10-15 \mathrm{~mm}) \\
+1 \times(\text { no. of small stalks, }<10 \mathrm{~mm}) . \\
\text { wPercent marketable yield. } \\
\text { "Large-medium fern index }=3 \times(\text { no. of large stalks, }>15 \mathrm{~mm})+2 \times(\text { no. of medium stalks, } 10- \\
15 \mathrm{~mm}) \text {. } \\
\text { uTotal fern number. } \\
{ }^{* * * *, \text { Ns }} \text { Significant at } P=0.05 \text { and } 0.01 \text {, respectively, or nonsignificant. }\end{array}$} \\
\hline
\end{tabular}

yield and the products of seasonal PMY and both fern vigor indices and stalk count for each year. Correlations were also calculated for data averaged over years. In addition, the product of PMY for each day of each year and LMFI of that year were calculated. These values and daily averages over years were used to estimate correlation coefficients with marketable yield averaged for 2 years.

Daily harvest data were also considered for two sets of dates. Set one included days 5, 12, 19, 26, 33, 40, and 47, and set two included days $7,14,21,28,35,42$, and 48. Day 1 corresponded to 27 Apr., the earliest harvest date for either year of the study. PMY in each year for each set of dates was calculated for the individual dates, the mean for each of the 21 possible 2-day combinations, and the mean for each of the 35 possible 3-day combinations. The PMY estimates for each genotype were multiplied by its LMFI for the same year, and the products were averaged for the two years of the study. Pearson correlation coefficients were calculated between these values, both for single year and average data and mean marketable yield. The correlations were then calculated without dates 5 and 7 in sets 1 and 2, respectively.

The analysis was repeated using total yield in place of fern index. The products of mean LMFI and PMY (single, 2-day, and 3-day combinations), each averaged over years, were also used in a correlation analysis.

Table 3. Pearson correlation coefficients $(r)$ between large-medium fern index $(\text { LMFI })^{z}$ and total yield for individual years.

\begin{tabular}{lcc}
\hline \hline & \multicolumn{2}{c}{ Total yield } \\
\cline { 2 - 3 } LMFI year & 1990 & 1991 \\
\hline 1989 & $0.88^{* *}$ & $0.82^{* *}$ \\
1990 & $0.90^{* *}$ & $0.88^{* *}$ \\
1991 & $0.75^{* *}$ & $0.78^{* *}$
\end{tabular}

$\overline{\mathrm{z}} 3 \times($ no. of large stalks, $>15 \mathrm{~mm})+2 \times($ no. of medium stalks, $10-15 \mathrm{~mm})$ ${ }^{* *}$ Significant at $P=0.01$. 
Table 4. Pearson correlation coefficients $(r)$ between marketable yield and the product of largemedium fern index (LMFI) ${ }^{2}$ and percent marketable yield (PMY).

\begin{tabular}{lllll}
\hline & & \multicolumn{2}{c}{ Marketable yield } \\
\cline { 3 - 4 } LMFI & PMY & 1990 & 1991 & Mean \\
\hline 1989 & 1990 & $0.94^{* *}$ & $0.69^{* *}$ & $0.81^{* *}$ \\
1990 & 1990 & $0.96^{* *}$ & $0.80^{* *}$ & $0.89^{* *}$ \\
1990 & 1991 & $0.85^{* *}$ & $0.96^{* *}$ & $0.98^{* *}$ \\
1991 & 1991 & $0.83^{* *}$ & $0.94^{* *}$ & $0.96^{* *}$ \\
\hline
\end{tabular}

$3 \times$ (no. of large stalks, $>15 \mathrm{~mm})+2 \times$ (no. of medium stalks, $10-15 \mathrm{~mm}$ ).

${ }^{* *}$ Significant at $P=0.01$.

\section{Results}

Correlations between yield variables averaged over years. For yield and fern data averaged over 2 and 3 years, respectively, total fern number (TFN), TFI, and LMFI were correlated with total yield but not marketable yield (Table 2). Total yield was most associated with LMFI, while total harvested spear count was most associated with TFI and TFN.

Marketable yield was highly correlated with the products of seasonal PMY and the three fern variables: TFN, TFI, LMFI (Table 2), but not with fern indices nor fern count alone.

Correlations between variables for individual years. LMFIs calculated during the late summer before or after the harvest season were not consistently better or worse for predicting total yield in a given year (Table 3). Correlation coefficients between 1989 or 1990 fern indices and 1990 yield were similar, and the 1989 and 1990 fern indices were better predictors of 1991 yield than the 1991 index.

The products of seasonal PMY in 1990 and LMFI in 1989 or 1990 were good predictors of 1990 marketable yield (Table 4). Identical results were observed for correlations between 1991 marketable yield and the products of 1991 PMY and 1990 or 1991 fern indices. Mean marketable yield was highly correlated with the products of PMY and fern index for individual years, and correlations using the 1991 PMY data were highest (0.96 to 0.98).

Correlations between variables using daily harvest records. Correlations between marketable yield averaged over years and the products of PMYs for individual dates within each year and the LMFI for that same yearranged from- 0.06 to 0.95 and from -0.32 to 0.97 in 1990 and 1991, respectively (Fig. 1). The $1991 r$ values stabilized at high levels $(r>0.70)$ after 2 weeks (Fig. 1B); however, in 1990, consistently large correlations were not observed until the 5th week (Fig. 1A). Coefficient means were 0.70 and 0.75 in 1990 and 1991, respectively.
When the products of PMY and fern indices were averaged over 2 years, the mean of correlation coefficients was $0.80 \pm 0.03$, and values ranged from 0.58 to 0.96 (Fig. 1C). Among daily $r$ values $79 \%$ were $\geq 0.80$ and $33 \%$ were $\geq 0.90$. If the first 2 weeks of harvest were eliminated, $89 \%$ and $39 \%$ of the coefficients were $\geq 0.80$ and 0.90 , respectively.

Correlations between variables for two sets of single-day estimates of PMY. For the two sets of dates selected in 1990 and $1991,0 \%$ to $14 \%$ of correlation coefficients between mean marketable yield and the product of PMY on individual dates in each year and the LMFI for the corresponding year were $\geq 0.90$ (Table 5). One-third or fewer of the coefficients were $\geq 0.90$ for either set of dates when the products of PMY and fern index were averaged over years.

Correlations between variables with 2-day averages of PMY for two sets of dates. For all possible 2-day average estimates of PMY in either year, $<20 \%$ of the correlation coefficients were $\geq 0.90$ (Table 5). When the products of PMY for 2-day combinations and fern vigor indices were averaged for 2 years, the proportion of correlation coefficients $\geq 0.90$ increased to nearly $60 \%$. After data for days 5 and 7 were eliminated from sets 1 and 2, respectively, $87 \%$ and $80 \%$ of the correlation coefficients were $\geq 0.90$, respectively, and all were $\geq 0.87$.

Correlations between indicators with 3-day averages for PMY for two sets of dates. When PMY was averaged for all 3-day combinations, the proportion of correlations coefficients with high $(r \geq$ $0.90)$ values increased relative to 2 -day combinations and singleday data (Table 5). For individual years, $0 \%$ to $31 \%$ of correlation coefficients were $\geq 0.90$. When the product of PMY and fern index was averaged over years, $60 \%$ of the correlations for 3-day combinations were $\geq 0.90$. After days 5 and 7 were dropped from the analysis, $95 \%$ and $100 \%$ of the correlations were $\geq 0.90$, respectively, and all were $\geq 0.88$.

Alternative predictors of marketable yield. When the analysis

Table 5. Percentage of Pearson correlation coefficients $\geq 0.90$ between mean marketable yield and product of large-medium fern index (LMFI) ${ }^{2}$ and percent marketable yield (PMY); PMY was estimated for two sets of individual days, all possible 2- and 3-day combinations, and products were calculated for individual years and averaged over years.

\begin{tabular}{|c|c|c|c|c|c|c|c|c|}
\hline \multirow[b]{3}{*}{ Date combinations } & \multicolumn{8}{|c|}{$\mathrm{LMFI} \times \mathrm{PMY}$} \\
\hline & \multicolumn{2}{|c|}{1990} & \multicolumn{2}{|c|}{1991} & \multicolumn{2}{|c|}{ All days } & \multicolumn{2}{|c|}{$\begin{array}{l}\text { First day } \\
\text { excluded }^{y}\end{array}$} \\
\hline & Set $1^{x}$ & Set $2^{w}$ & Set 1 & Set 2 & Set 1 & Set 2 & Set 1 & Set 2 \\
\hline Individual & 0 & 14 & 14 & 14 & 29 & 14 & 33 & 17 \\
\hline 2-day & 0 & 14 & 19 & 19 & 62 & 57 & 87 & 80 \\
\hline
\end{tabular}

$\overline{8} 3 \times$ (no. of large stalks, $>15 \mathrm{~mm})+2 \times($ no. of medium stalks, $10-15 \mathrm{~mm})$.

'Excluding date 5 in set 1 and 7 in set 2 .

${ }^{x}$ Days $5,12,19,26,33,40,47$.

"Days 7, 14, 21, 28, 35, 42, 48 . 


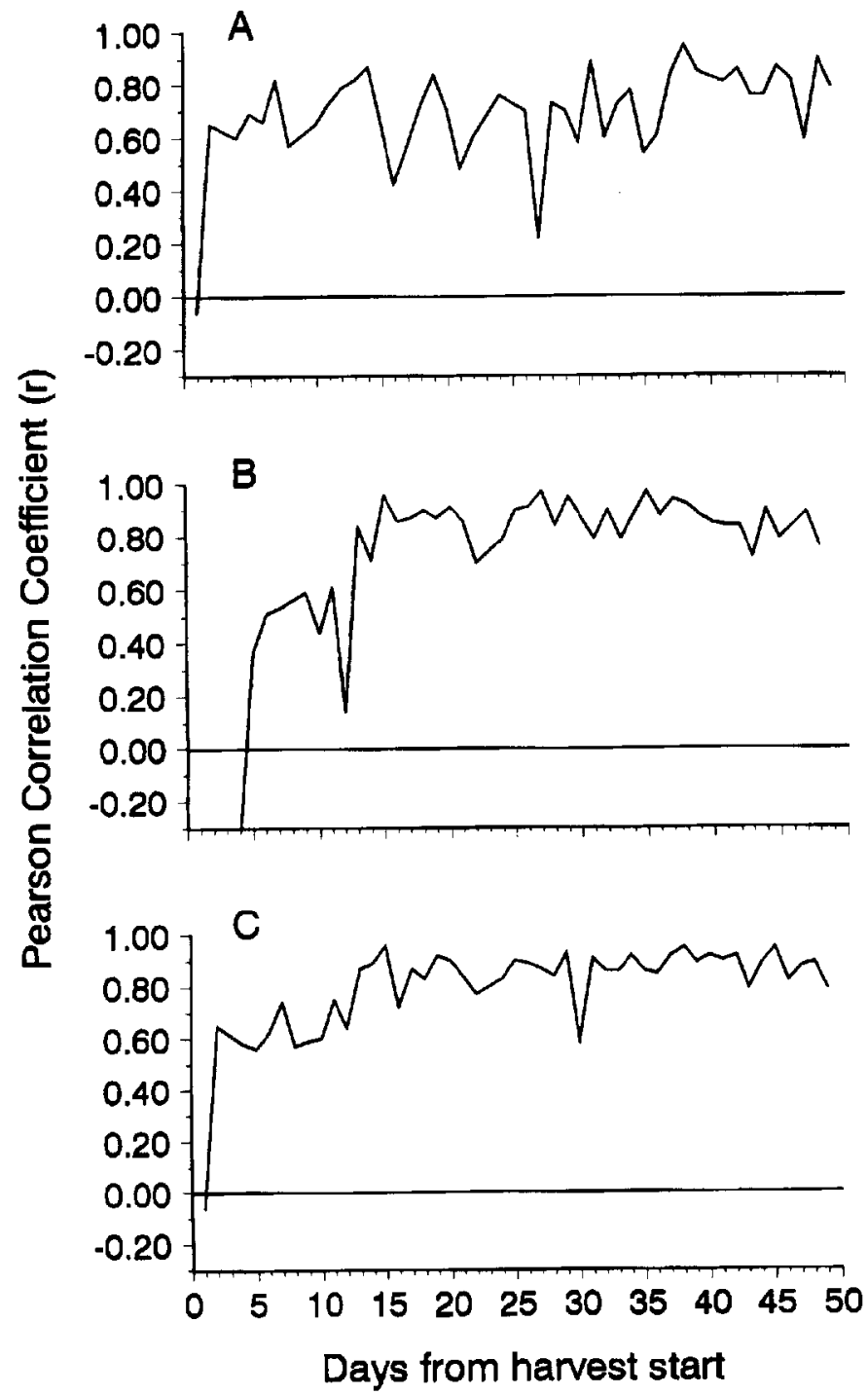

Fig. 1. Seasonal variation for correlation coefficients between mean marketable yield and the product of LMFI and daily estimates of PMY.(A) 1990, (B) 1991 (C) mean 1990-91. Day $1=$ start of harvest.

was repeated by multiplying PMY for individual dates or 2- and 3day averages with total yield, the distribution of correlation coefficients was similar (data not shown). Analogous results were obtained when the 3-year average estimates of fern vigor were multiplied by estimates of PMY averaged over years (data not shown).

\section{Discussion}

The fern vigor indices that consider all stalks or large and medium stalks were highly correlated with total yield. The former was less predictive than the latter $(r=0.75$ vs. $r=0.91)$, suggesting that the weight assigned to small stalks in the index is not predictive of actual yield. Total fern count was correlated $(r=0.59)$ with total yield but was less reliable than the other indicators.

Fern indices from the year before harvest or from the same year were equally good predictors of total yield in a season. The marketable yield from each year was highly correlated with the product of seasonal PMY in that same year and the fern vigor indices of the same or previous year, indicating fern index from either year may be used to predict marketable yield in a season.

When annual estimates of PMY were replaced with those from individual days, correlation coefficients were erratic over the season and between years. When two sets of dates were considered, the 5th and 7th days of each week, and the mean PMY for the 2- and 3-day combinations of dates within each set were used in conjunction with fern index to predict marketable yield, important trends were observed. Increasing the number of dates to estimate PMY increased the proportion of correlation coefficients between mean marketable yield and the product of fern index and PMY that were $\geq 0.90$. Averaging the products over years as well as eliminating data from the first week of harvest also improved correlation coefficients; $95 \%$ and $100 \%$ of correlations were $\geq 0.90$.

Since PMY at the beginning of the harvest period was not a good measure of seasonal values, the product of PMY for three harvest dates, mid- to late-season, and fern index can be a reliable estimate of marketable yield. Total yield can also be used in place of fern index; the fern vigor indices and total yield were highly correlated

In this study, the product of-fern index and PMY each averaged over years was as good a predictor of marketable yield as the average of the products for the 2 indicators. However, the latter variable is preferred. Over the course of a long-term trial, lasting up to 10 years, yields can vary, increasing significantly as the crowns mature, or decreasing if the crowns become diseased. PMY is affected by climate, and should be consistent across genotypes over years, but a decline of vigor may result in production of small, inferior, unmarketable spears and affect PMY inconsistently over the lifetime of a field. Thus, for long-term evaluations, the cumulative products of PMY and fern index for each year may be better estimates of yield for the life of a field than the product of mean PMY and fern index, each averaged over years.

\section{Literature Cited}

Bussell, W.T., P.G. Falloon, and A.S. Nikoloff. 1987. Evaluation of asparagus yield performance after two years' harvesting. New Zealand J. Expt. Agr. 15:205-208.

Coyne, D.P. 1967. Correlation studies in asparagus in relation to cumulative season yield. Hort. Res. 7: 105-112.

Currence, T.M. and A.L. Richardson. 1937. Asparagus breeding studies. Proc. Amer. Soc. Hort. Sci. 35:554-557.

Ellison, J.H. and D.F. Scheer. 1959. Yield related to brush vigor in asparagus. Proc. Amer. Soc. Hort. Sci. 73:339-344.

Ellison, J.H., G.B. Reynard, D.F. Scheer, and J.J. Wagner. 1960. Estimating comparative yields of asparagus strains without full season harvest records. Proc. Amer. Soc. Hort. Sci. 76:376-381.

Falloon, P.G. and A.S. Nikoloff. 1986. Asparagus: Value of individual plant yield and fern characteristics as selection criteria. New Zealand J. Expt. Agr. 14:417-420.

Ito, P.J. and T.M. Currence. 1965. Inbreeding and heterosis in asparagus. Proc. Amer. Soc. Hort. Sci. 86:338-346.

Jamieson, J.L., T.Y. Slimmon, and H. Tiessen. 1985. Time required to establish tissue culture clones, p 89-96. In: E.C. Lougheed and H. Tiessen (eds.). Proceedings of the sixth international asparagus symposium. Univ. of Guelph, Ont., Canada, 5-9 Aug. 1985.

Moon, D.M. 1976. Yield potential of Asparagus officinalis L. New Zealand J. Expt. Agr. 4:435-438.

Young, R.E. 1937. Yield-growth relationships in asparagus. Proc. Amer. Soc. Hort. Sci. 35:576-577. 